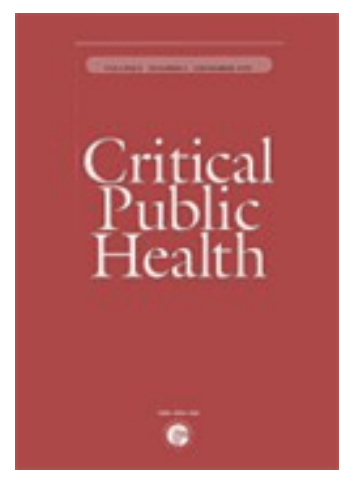

NHS health trainers: a review of emerging evaluation evidence

\begin{tabular}{|r|l|}
\hline Journal: & Critical Public Health \\
\hline Manuscript ID: & CCPH-2010-0055.R2 \\
\hline Manuscript Type: & Paper \\
\hline Keywords: & Health, Evaluation, Evidence \\
\hline \\
\\
\\
\end{tabular}




\title{
NHS health trainers: a review of emerging evaluation evidence
}

\author{
Authors: \\ Pamela Attree ${ }^{1}$ \\ School of Health and Medicine \\ Division of Health Research \\ Bowland Tower East \\ Lancaster University \\ Lancaster LA1 4YT \\ Tel. 01524594103 \\ E mail: p.attree@lancaster.ac.uk \\ Stephen Clayton ${ }^{2}$ \\ Sakthi Karunanithi ${ }^{3}$ \\ Shilpa Nayak ${ }^{3}$ \\ Jennie Popay ${ }^{4}$ \\ Donald $\operatorname{Read}^{3}$
}

\footnotetext{
${ }^{1}$ Senior Research Associate, School of Health and Medicine, Division of Health Research, Bowland Tower East, Lancaster University.

${ }^{2}$ University Teacher, Department of Health Inequalities and Social Determinants of Health, Institute of Psychology, Health and Society, University of Liverpool.

${ }^{3}$ Specialist Registrar in Public Health, North West School of Public Health, Mersey Deanery, Liverpool.

${ }^{4}$ Professor of Sociology and Public Health, School of Health and Medicine, Division of Health Research, Bowland Tower East, Lancaster University.
} 


\section{Acknowledgements}

This work was funded by NHS Cumbria, Liverpool NHS Primary Care Trust, North Lancashire NHS Teaching Primary Care Trust, NHS Sefton and NHS Wirral. We would like to thank Professor Margaret Whitehead and Dr. Barbara Hanratty of the University of Liverpool, and Dr. Sara Mallinson of Lancaster University for their contributions to the scoping work and the discussions which have shaped our thinking about this paper. No conflicts of interest have been identified. 


\title{
NHS health trainers: a review of emerging evaluation evidence
}

\author{
Abstract \\ Recent years have seen a change in focus in UK public health policies towards an emphasis \\ on individual lifestyle choices. As part of this shift, NHS health trainers were introduced in \\ disadvantaged communities in England, to provide peer support to people 'at risk' of \\ developing lifestyle-related health problems and to help them to self manage their behaviour. \\ Concerns have been expressed, however, about the strength of the evidence supporting the \\ initiative.
}

This paper outlines a number of gaps between the theory and rhetoric underpinning the NHS health trainer initiative, and the reality in practice. The paper critiques the evaluation evidence, questions the assumption that engaging lay people in health promotion activities in place of health professionals is necessarily a preferable option, identifies inconsistencies in the evidence supporting individually-based health improvement initiatives, and suggests that interventions which target deprived areas but neglect the social determinants of health may be limited in their effectiveness.

Keywords: health, evaluation, evidence 


\section{Introduction}

Recent years have seen significant reforms in UK public health policies which one commentator has characterised as a shift from a public to a private conception of public health (Hunter 2005), and another as neglecting the need to address both individual and wider determinants of health (Trayers and Lawlor 2007). This shift moves the focus of public health policies away from factors that affect individual health that are (largely) outside the control of the individual (poverty, employment, education etc.) and focuses instead on the role of individual lifestyle choices as the key to promoting better public health (Hunter et al 2010). As part of this shift, the UK government's 2004 White Paper Choosing health: making healthy choices easier, signalled the intention to introduce NHS health trainers into disadvantaged areas of England, to provide one-to-one support to encourage people in 'at risk' groups to make healthier lifestyle choices (Department of Health 2004). Launched in 2005 in twelve pilot sites, a commitment was made by the government to establish the initiative in Spearhead Group Primary Care Trusts (the fifth of areas with the worst health and deprivation indicators compared to England) from April 2006 and throughout the country from 2007 (Department of Health 2004).

Focused on providing 'advice from next door' to people within disadvantaged communities 'at risk' of developing health problems and supporting them to set behavioural goals and to self manage their behaviour, it was anticipated that one of the 
outcomes of the initiative would be to reduce health inequalities (Department of Health 2008a, 2008b).

The evidence base supporting the introduction of health trainers is not clearly defined and is, at best, limited (Gould 2009). The main body of research that appears to have influenced the introduction of the scheme is drawn from a range of programmes across the world involving trained lay people, such as community health workers, lay health workers or advisors typically involved in providing primary health care to local populations (Oxford Policy Management 2002, Visram and Drinkwater 2005, Zhang and Unschuld 2008). Although we do not wish to explore the usefulness of this evidence as a base for the health trainer initiative, a key point about this evidence needs emphasising. Much of this evidence relates to providing basic health care in situations where little or no formal health services exist or are unavailable to the majority of the population. In contrast, health trainers' role is to provide advice and motivation for their clients.

In this paper, we outline and unpack the underlying theory of change or programme logic of NHS health trainer programme to explore the assumptions underpinning the programme. We then examine this theory and rhetoric in the light of the available evaluation evidence, and contextualise these findings within some of the wider critiques of individual behavioural approaches to health improvement. We conclude by asking to what extent the NHS health trainer initiative is able to improve health outcomes and reduce health inequalities in disadvantaged communities without the support of efforts to tackle more macro-level structural inequalities. 


\section{THEORY and RHETORIC}

\section{The programme logic underpinning the NHS health trainer scheme}

Social interventions, such as the NHS health trainer initiative, can be viewed as having an underlying programme logic or theory of change (Whitehead 2007). Often not explicitly stated, this theory (or theories) links the definition of the problem to the proposed outcomes of the programme that will address the problem. In this section, we unpack the underlying programme logic of the health trainer initiative to examine how the programme defined the 'problem' it was designed to address and how it proposed (theoretically) to address this perceived 'problem'. In a following section, we describe the limitations of the evaluation evidence and examine the extent to which it evaluates the initiative in terms of these logic models.

The logic models invoked in the health trainer initiative are underpinned by three perceived problems, which are then addressed by the theory of change embedded in the initiative. The first perceived problem is that people living in more deprived areas or from more vulnerable groups have more risky health behaviours and make 'poorer' health choices. This leads to the theory that targeting of the initiative, and thus the provision of advice, education, and signposting to services, in more deprived areas and on 'harder to reach' populations, will be of more benefit to those who most need the service, and thereby have the potential to reduce health inequalities. 
The second perceived problem is that 'harder to reach' individuals, that is those from disadvantaged areas or belonging to vulnerable groups, do not access mainstream health services in sufficient numbers, and ignore, do not trust, or do not believe in existing health promotion efforts. The theory of change here is that individuals who are from these areas/groups, who understand the experiences and concerns of the target individuals and have a shared interest in improving their health, will be able to effect change. From this perspective, a non-health professional drawn from the local area is a more acceptable source of information and better able to engage with clients from harder to reach groups; moreover, their 'localness' may mean that people in disadvantaged communities perceive them as more approachable.

The third perceived problem is that undesirable health outcomes are largely the result of the 'poor' health behaviours and choices of individuals. This leads to a theory of change which posits that health trainers can motivate and train individuals to set their own improved behavioural goals, manage their own health behaviours and the events and circumstances in their lives which they would like to change. This approach reflects the ‘fully engaged scenario’ proposed by Wanless (2002, 2004), which portrays citizens as actively involved with the notion of healthy living, and perceives health-related lifestyle advice as part of a 'concerted effort to increase focus on individual responsibility in health management' (Lhussier and Carr 2008, p301). From this perspective, this can be achieved using techniques drawn from behavioural psychology, such as (amongst others) social cognitive theory (Bandura 1989, 1998) and the influential transtheoretical (or stages of change) model (Prochaska and DiClemente 1982). The assumption is that 
influencing individuals to make 'better' health and lifestyle choices will improve both individual and overall public health.

\section{PUTTING THEORY INTO PRACTICE: THE REALITY}

Whether the theory underpinning these initiatives is borne out in practice is an important question. To address this question we carried out a scoping review of evidence relevant to the NHS health trainer initiative, using methods adapted from the framework described by Arksey and O’Malley (2005), as part of a wider mapping study of public investment in policies and interventions aimed at addressing the social determinants of health and tackling health inequalities. Two main sources of evidence regarding the NHS health trainer programme were identified: first, from a series of annual audit reports of national data, and reports from the national Health Trainer Data Collection and Reporting System (DCRS). National audits provide information collated annually about health trainer personnel and clients, stage of development of local services, and funding (Wilkinson et al 2007, 2008, Smith et al 2008, 2010): together with local evaluation data (Wilkinson et al 2008). DCRS reports include data on the number of clients using the service, health trainers' characteristics, and client-centred questions regarding access to the service, behaviours targeted, goal setting and outcomes (Hopkinson and Fidan 2009, Fidan et al 2009). Second, a limited number of stand-alone local evaluations of NHS health trainer schemes were identified (See Table 1).

\section{insert Table 1 about here.}




\section{Evaluation findings}

National reports chart the rapid growth of the NHS health trainer programme: in 2008-2009, 169 health trainer services were in operation across 115 Primary Care Trusts (Smith et al 2010). A broad range of disadvantaged communities and groups perceived as vulnerable to the risk of experiencing poor health were targeted by services (Smith et al 2010). The most frequent topics on which health trainers were consulted were diet $(61 \%)$ and physical exercise (27\%) (Fidan et al 2009). Positive outcomes reported include good uptake of the service, increased access to preventative services for clients, psychological, emotional and social benefits and achievement of behavioural goals (in particular smoking cessation) (Wilkinson et al 2008).

Local evaluations of the scheme are also broadly positive in their findings (Visram and Geddes 2007), suggesting that health trainers can provide the type of support necessary to help individuals make desirable lifestyle changes (Ball et al 2008, 2009b, Kime et al 2008, Meah and Guest 2010). Across a number of initiatives, clients spoke positively about their experiences of the service (Kime et al 2008, Ball et al 2008, 2009b, Meah and Guest 2010). In one area, health trainers were seen as a way of facilitating communication between community members and the Primary Care Trust, and thus as a means of translating key health messages (Kitchen 2009). Health trainers were also perceived as filling a gap in services in disadvantaged communities (Visram et al 2006, Kitchen 2009). From health trainers' perspectives, the role was described as a source of personal fulfilment and career development (South et al 2006, 2007, Visram et al 2006, Kime et al 2008). However, the introduction of the scheme was not without its tensions, 
especially where there was a perceived overlap between the roles of health trainers and existing workers (South et al 2006, 2007, Visram and Geddes 2007, Ball et al 2008, 2009b).

\section{Limitations of the evaluation evidence}

Taken overall, the evidence base concerning the health trainer initiative has important limitations. There is a notable lack of research evaluating the impact of the NHS health trainer role, the extent to which the initiative leads to health improvements for clients, and whether it is cost effective, although it is acknowledged that it is relatively early in the life of the scheme for robust outcome evidence to be available (a number of studies, including a national evaluation, are ongoing) (Ball et al 2009b).

Although national reports contain a good deal of descriptive data concerning the NHS health trainer scheme, there is a paucity of data in the public domain about its effectiveness in bringing about health improvement or reducing health inequalities in disadvantaged communities. There are a number of problems inherent in the evidence base. Firstly, the national data set is incomplete. In 2008 to $2009,62 \%$ of NHS health trainer services were included in the DCRS (a further $30 \%$ were planning to use the system), while information concerning completion of Personal Health Plans (a health ‘stock-take' which records clients' goals and achievements) was limited (Smith et al 2010). Secondly, the focus of national reports is primarily on outputs (e.g. the number of clients reached by services) rather than outcomes in terms of delivering behaviour change (Smith et al 2008). Thirdly, whether health trainers are successfully tackling inequalities 
in the areas they serve is inferred by the approach and reach of initiatives, rather than substantive outcomes (Wilkinson et al 2008). Finally, there are limitations in the national evidence base regarding data quality. For example, local evaluations synthesised in national reports were typically non-experimental, observational studies of the processes and/or outcomes of health trainer services, usually collected at a single time point (i.e. cross-sectionally) (Wilkinson et al 2008). Behaviour or health outcome measures were not stated clearly in the majority of evaluations and few studies employed comparison or control groups or localities.

Local evaluations of the NHS health trainer scheme also have notable weaknesses. Firstly, there are problems with the generalisability of findings, as service models vary both between and within sites (because of differing local priorities) (South et al 2006, Visram et al 2006, Kitchen 2009). Secondly, no local evaluations included in this paper employed comparison areas or groups; the majority involved relatively small samples of stakeholders, often self selected, whose views may not be representative of wider constituencies (Visram et al 2006, Visram and Geddes 2007, Ball et al 2008, 2009a, Meah and Guest 2010). Typically, only clients who agreed to be followed up were asked for their views of the health trainer service (South et al 2006, 2007, Kime et al 2008), and it is possible that such samples were biased towards those with more positive experiences. Thirdly, the collection of service performance data is inconsistent, meaning that assessing client outcomes over time is difficult (Ball et al 2008, 2009a, 2009b, Kime et al 2008); importantly, therefore, we learn little about the sustainability of behaviour change. 
Although this type of approach to evaluation provides a great deal of valuable contextual detail regarding the process of implementing health trainer services, it is less useful in assessing the outcomes in terms of lifestyle change and health improvement.

It is also clear that evaluations have not addressed the logic models underpinning the health trainer initiative in any depth. Apart from some limited discussion about the desirability of employing a local person with community knowledge in the health trainer role (cf. South et al 2006, Visram and Geddes 2007, Ball et al 2008, Kime et al 2008, Kitchen 2009), the assumptions on which the scheme is based remain unexamined. In contrast, the adoption of a theory-based or realist approach to evaluation would place the emphasis on identifying the underlying programme logic - articulating in advance how intervention activities would be expected to lead to outcomes for recipients, and crucially, in what contexts (Judge and Bauld 2001, Parry and Judge 2005).

\section{WIDER CRITIQUES OF THE LOGIC MODELS}

One of the assumptions underpinning the NHS health trainer initiative is that a knowledgeable local person, who understands the experiences and concerns of clients, is likely to prove a more effective agent of change than a health professional, who may be perceived as remote by the community they serve. However, findings from studies of the effectiveness of engaging lay peers in health promotion activities, in comparison to health professionals, are inconsistent, and vary for different groups of people, by age, gender, ethnicity and risk-group membership (Durantini et al 2006). There is a need, therefore, 
for further research comparing the relative effectiveness of lay people and professional health care providers in bringing about health improvement (Lewin et al 2005), and to identify populations in which lay helper models work most successfully, in order to tailor interventions to individuals and groups from diverse cultures and backgrounds (Durantini et al 2006, Norris et al 2006, Brownstein et al 2007).

NHS health trainers' practice draws heavily on techniques from behavioural psychology to deliver sustained health improvement through individual behaviour change (Department of Health, 2008a). However, the research literature evaluating the relevance and use of individual behaviour change models is inconsistent and does not support any particular approach or strategy (NICE 2007). To take one example, the 'stages of change' theoretical model (Prochaska and DiClemente 1982) has been found to lack evidence of effectiveness (West 2005), particularly in relation to bringing about lasting behavioural change (Moore and Charvat 2007). A systematic review of the effectiveness of interventions based on a stages-of-change approach found that there was little evidence to suggest that stage-based behaviour change interventions are more effective than non-stage-based interventions (Riemsma et al 2002, 2003). A number of randomised trials of individual-level interventions to increase physical activity have also failed to demonstrate their long-term effectiveness (Harland et al 1999, Foster et al 2005, NICE 2006, Kinmonth et al 2008).

The NHS health trainer initiative is informed by an individual-responsibility model of health inequalities, which broadly sees undesirable adult health behaviours, such 
as smoking, as primarily the result of poor personal choices (McGinnis and Foege 1993, Patterson et al 1994, Wayland 2002, Morgan and Ziglio 2007). Public health initiatives influenced by this philosophy seek to address lifestyle management issues mainly through health education (Lynch et al 1997). An alternative model for addressing health inequalities emphasises the effects of socio-economic status, social conditions and social relations on health (Dahlgren and Whitehead 2007, Trayers and Lawlor 2007), arguing that policies which focus on individual health education alone and fail to engage with the material conditions in which people live are unlikely to improve the health of disadvantaged populations (Butterfoss et al 1993, Lynch et al 1997). Rather, policies which aim for a modest redistribution of wealth are seen as more likely to have an impact on health inequalities (Mitchell et al 2000). According to this model, the primary role of social policy should be to shape an environment, for example through methods such as increasing employment opportunities or the accessibility of healthy foods, which enables individuals to make healthier choices (Exworthy et al 2003). There is scant evidence, however, to suggest that NHS health trainers are working with communities to address the social determinants of health.

\section{Conclusions}

In this paper we have outlined a number of gaps between the theory and rhetoric underpinning the NHS health trainer scheme, and the reality in practice. Deficiencies in the evidence base have been discussed, and it is suggested that further research is needed to test the assumption that lay people are more effective than health professionals in 
promoting health improvement for 'at risk' populations. Questions have been raised about the strength of the evidence supporting individual behaviour change strategies, and the limitations of introducing individually-based interventions into disadvantaged communities while neglecting the social determinants of health. Evidence that health inequalities can be decreased by initiatives that target disadvantaged groups or areas is lacking (Lynch et al 1997), primarily because of a failure to take the effect of social circumstances into account (Lee et al 2008).

A lack of evidence has not precluded the national roll out of the NHS health trainer scheme, however. Critics suggest that there is a tendency for health policy to advance in parallel with the development of the evidence, introducing interventions based on assumptions of effectiveness, in place of evaluation data from pilot initiatives (Bonner 2003, Sowden and Raine 2008). Policymakers argue, however, that action often needs to be taken whether or not 'strong' evidence is available, and that pragmatic considerations, such as cost, may prevail over the perceived weight the UK government places on evidence-based practice (Petticrew et al 2004).

Although the health trainer scheme has adopted a number of different service models (Visram and Drinkwater 2005, Visram et al 2006), over time there has been a notable shift towards focusing on individual behavioural change (Smith et al 2008), reflecting the thrust of public health policy in general (Graham 2009). Doubts have been expressed about the effectiveness of interventions which concentrate on changing individual behaviour, while ignoring or sidelining the social determinants of health 
(Macintyre 2007). A major stumbling block to the introduction of initiatives which target health inequalities more broadly, however, particularly in times of economic cutbacks, is that while schemes that utilise lay people in advisory roles are relatively easy and inexpensive to implement - hence their popularity with governments - tackling the social determinants of health is comparatively costly and time consuming (Wayland 2002). 


\section{References}

Arksey, H. and O’Malley, L., 2005. Scoping studies: towards a methodological framework. International Journal of Social Research Methodology, 8 (1), 19-32.

Ball, L. et al., 2008. Evaluation of the North East Lincolnshire health trainer programme: final report. Sheffield Hallam University, Centre for Health and Social Care Research.

Ball, L. O'Kasheh, R. and Qutishat, D., 2009a. Evaluation of health trainers working in primary care. Sheffield Hallam University, Centre for Health and Social Care Research.

Ball, L. O'Kasheh, R. and Whitfield, M., 2009b. Summary evaluation of the North East Lincolnshire health trainer services. Sheffield Hallam University, Centre for Health and Social Care Research.

Bandura, A., 1989. Human agency in social cognitive theory. American Psychologist, 44, 1175-1184.

Bandura, A., 1998. Health promotion from the perspective of Social Cognition Theory, Psychology and Health, 13, 623-649.

Bonner, L., 2003. Using theory-based evaluation to build evidence-based health and social care policy and practice. Critical Public Health, 13(1), 77-92.

Brownstein, J.N. et al., 2007. Effectiveness of community health workers in the care of people with hypertension. American Journal of Preventive Medicine, 32(5), 435447. 
Butterfoss, F.D. Goodman, R.M. and Wandersman A., 1993. Community coalitions for prevention and health promotion. Health Education Research: Theory \& Practice, 8(3), 315-330.

Dahlgren, G. and Whitehead, M., 2007. European strategies for tackling social inequities in health: Levelling up Part 2. Denmark: World Health Organization, Regional Office for Europe.

Department of Health, 2004. Choosing health: making healthy choices easier. London: The Stationery Office.

Department of Health, 2008a. Improving health: changing behaviour: NHS health trainer handbook. London: DH Publications.

Department of Health, 2008b. Health trainer strategic aim and objectives 2009-11. [online] Available from: http://www.dh.gov.uk/prod_consum_dh/groups/dh_digitalassets/documents/digita lasset/dh_100880.pdf [Accessed 17 February 2010]

Durantini, M.R. et al., 2006. Conceptualizing the influence of social agents of behaviour change: a meta-analysis of the effectiveness of HIV prevention interventionists for different groups. Psychological Bulletin, 132(2), 212-248.

Exworthy, M. Bland, D. and Marmot, M., 2003. Tackling health inequalities in the United Kingdom: the progress and pitfalls of policy. Health Services Research, 38(6), 1905-1922.

Fidan, E. Hopkinson D. and N'Kongolo, R.K., 2009. National health trainer data collection and reporting system: system update \& initial responses to national 
reporting framework 'key questions'. Birmingham Primary Care Shared Services Agency.

Foster, C. Hillsdon, M. and Thorogood, M., 2005. Interventions for promoting physical activity. Cochrane Database of Systematic Reviews, Issue 1, Article No. CD003180.

Gould, M., 2009. Can health trainers reduce poor health? Health Service Journal. [online] 24 April 2009. Available from:

http://www.hsj.co.uk/resource-centre/can-health-trainers-reduce-poorhealth/2007724.article [Accessed 17 February 2010]

Graham, H., 2009. Health inequalities, social determinants and public health policy. Policy \& Politics, 37(4), 463-479.

Harland, J. et al., 1999. The Newcastle exercise project: a randomized controlled trial of methods to promote physical activity in primary care. British Medical Journal, $319,828-32$.

Hopkinson, D. and Fidan, E. 2009. National health trainer data collection and reporting system: updated national report - February 2009. Birmingham Primary Care Shared Services Agency.

Hunter, D., 2005. Choosing or losing health? Journal of Epidemiology and Community Health, 59 (12), 1010-1013.

Hunter, D.J. et al., 2010. Getting to grips with health inequalities at last? British Medical Journal, 340, 323-324.

Judge, K. and Bauld, L., 2001. Strong theory, flexible methods: evaluating complex community-based initiatives. Critical Public Health, 11(1), 19-38. 
Kime, N. South, J. and Lowcock, D., 2008. An evaluation of the Bradford District health trainers programme - Phase 2. Leeds Metropolitan University, Centre for Health Promotion Research.

Kinmonth, A. et al., 2008. Efficacy of a theory-based intervention to increase physical activity in an at-risk group in primary care (ProActive UK): a randomised trial. The Lancet, 371:41-48.

Kitchen, G., 2009. Health trainers in Cheshire and Merseyside. Liverpool: HM Partnership.

Lee, J.E.C. et al., 2008. Health risk perceptions as mediators of socioeconomic differentials in health behaviour. Journal of Health Psychology, 13, 1082-1091.

Lewin, S et al., 2005. Lay health workers in primary and community health care. Cochrane Database of Systematic Reviews, 2005, Issue 1, Article. No. CD004015.

Lhussier, M. and Carr, S.M., 2008. Health-related lifestyle advice: critical insights. Critical Public Health, 18(3), 299-309.

Lynch, J.W. Kaplan, G.A. and Salonen, J.T., 1997. Why do poor people behave poorly? Variation in adult health behaviours and psychosocial characteristics by stages of the socioeconomic lifecourse. Social Science and Medicine, 44(6), 809-819.

Macintyre, S., 2007. Inequalities in health in Scotland: what are they and what can we do about them? Occasional paper No 17. Glasgow: MRC Social and Public Health Sciences Unit.

McGinnis, J.M. and Foege, W.H., 1993. Actual causes of death in the United States. Journal of the American Medical Association, 18, 2207-2212. 
Meah, S. and Guest, S., 2010. An evaluation of the health trainer service across Greater Manchester. University of Salford, Greater Manchester Public Health Practice Unit.

Mitchell, R. Shaw, M. and Dorling, D., 2000. Inequalities in life and death: what if Britain were more equal? York: Joseph Rowntree Foundation.

Morgan, A. and Ziglio E., 2007. Revitalising the evidence base for public health: an assets model. Promotion and Education, 14, 17-22.

NICE (National Institute for Health and Clinical Excellence), 2006. A rapid review of the effectiveness of exercise referral schemes to promote physical activity in adults. London: NICE.

NICE (National Institute for Health and Clinical Excellence), 2007. Behaviour change at population, community and individual levels. NICE public health guidance 6 . London: NICE.

Norris, S.L. et al., 2006. Effectiveness of community health workers in the care of persons with diabetes. Diabetic Medicine, 23, 544-556.

Oxford Policy Management, 2002. Lady health worker programme: summary of final report. Oxford: Oxford Policy Management.

Parry, J. and Judge, K., 2005. Tackling the wider determinants of health disparities in England: a model for evaluating the New Deal for Communities regeneration initiative. American Journal of Public Health, 95(4), 626-628.

Patterson, R.E. Haines, P.S. and Popkin, D.M., 1994. Health life-style patterns of UnitedStates adults. Preventive Medicine, 23(4), 453-460. 
Petticrew, M. et al., 2004. Evidence for public health policy on inequalities: 1: The reality according to policymakers. Journal of Epidemiology and Community Health, 58, 811-816.

Prochaska, J.O. and DiClemente, C.C., 1982. Trans-theoretical therapy - toward a more integrative model of change. Psychotherapy: Theory, Research and Practice, 19(3), 276-288.

Riemsma, R.P. et al., 2002. A systematic review of the effectiveness of interventions based on a stages-of-change approach to promote individual behaviour change. Health Technology Assessment, 6(24).

Riemsma, R.P. et al., 2003. Systematic review of the effectiveness of stage based interventions to prevent smoking cessation. British Medical Journal, 326, 11751177.

Smith, D. Gardner, B. and Michie, S., 2008. National health trainer end of year report 07/08. London: Centre for Outcomes Research and Effectiveness, University College London.

Smith, D. Gardner, B. and Michie, S., 2010. Health trainers national end of year report: 2008-09. London: Centre for Outcomes Research and Effectiveness, University College London.

South, J. et al., 2006. An evaluation of the Bradford district health trainers programme: an early adopter site. Leeds Metropolitan University: Centre for Health Promotion Research. 
South, J. Woodward, J. and Lowcock, D., 2007. New beginnings: stakeholder perspectives on the role of health trainers. The Journal for the Royal Society for the Promotion of Health, 127, 224-230.

Sowden, S.L. and Raine, R., 2008. Running along parallel lines: how political reality impedes the evaluation of public health interventions. A case study of exercise referral schemes in England. Journal of Epidemiology and Community Health, 62, 835-841.

Trayers, T. and Lawlor, D.A., 2007. Bridging the gap in health inequalities with the help of health trainers: a realistic task in hostile environments? A short report for debate. Journal of Public Health, 29(3), 218-221.

Visram, S. and Drinkwater, C., 2005. Health trainers: a review of the evidence. Northumbria University.

Visram, S. et al., 2006. An evaluation of the early adopter phase of the health trainers project in the North East: final report. Northumbria University.

Visram, S. and Geddes, L., 2007. What does it mean to be a NHS health trainer? Further evaluation of the health trainers initiative in County Durham and Tees Valley: final report. Northumbria University.

Wanless, D., 2002. Securing our future health: taking a long-term view-final report. London: HM Treasury.

Wanless, D., 2004. Securing good health for the whole population - final report. London: HM Treasury.

Wayland, C., 2002. Acceptable and appropriate: programme priorities vs. felt needs in a CHW programme. Critical Public Health, 12(4), 335-350. 
West, R., 2005. Time for a change: putting the Transtheoretical (Stages of Change) model to rest. Addiction, 100, 1036-1039.

Whitehead, M., 2007. A typology of actions to tackle social inequalities in health. Journal of Epidemiology and Community Health, 61, 473-478.

Wilkinson, D. et al., 2007. National health trainer activity report (Based on end year reports 06/07). London: Centre for Outcomes Research and Effectiveness, University College London.

Wilkinson, D. et al., 2008. National health trainer outcome and evaluation synopsis. London: Centre for Outcomes Research and Effectiveness, University College London.

Zhang, D. and Unschuld, P. U., 2008. China's barefoot doctor: past, present, and future. The Lancet, 372 (9653), 1865-1867. 
Table 1: Evaluation studies

\begin{tabular}{|c|c|c|c|c|}
\hline $\begin{array}{l}\text { Author(s) } \\
\text { and date }\end{array}$ & Focus of study & Study methods & Sample & Limitations of study \\
\hline $\begin{array}{l}\text { Ball et al } \\
2008\end{array}$ & $\begin{array}{l}\text { Evaluation of the } \\
\text { North East } \\
\text { Lincolnshire } \\
\text { health trainer } \\
\text { service. }\end{array}$ & $\begin{array}{l}\text { Secondary analysis: client data set } \\
\text { 2007-2008; post-engagement } \\
\text { client satisfaction survey (at } 3 \text { and } \\
6 \text { months). } \\
\text { Qualitative methods: interviews } \\
\text { (face to face and telephone), and } \\
\text { focus groups. }\end{array}$ & $\begin{array}{l}\text { Interviews with } 8 \text { key } \\
\text { stakeholders and } 4 \\
\text { clients. Focus groups } \\
\text { with } 10 \text { health trainers. } \\
\text { Client satisfaction } \\
\text { survey - } 59 \text { respondents } \\
\text { (46\% response rate). }\end{array}$ & $\begin{array}{l}\text { Consistency of data collection } \\
\text { e.g. follow-up data at } 3 \text { and } 9 \\
\text { months difficult to capture; } \\
\text { sample may be biased in favour } \\
\text { of service. Service performance } \\
\text { comparison data pre- and post- } \\
\text { intervention ( } 2007-2008) \\
\text { included a high proportion of } \\
\text { missing cases, making statistical } \\
\text { comparisons difficult. }\end{array}$ \\
\hline $\begin{array}{l}\text { Ball et al } \\
2009 a\end{array}$ & $\begin{array}{l}\text { Evaluation of } \\
\text { health trainers } \\
\text { working in } \\
\text { primary care in } \\
\text { North East } \\
\text { Lincolnshire. }\end{array}$ & Qualitative methods: interviews. & $\begin{array}{l}\text { Convenience sample of } \\
8 \text { health care staff and } 2 \\
\text { health trainers across } 3 \\
\text { primary care practices. }\end{array}$ & $\begin{array}{l}\text { Service performance data } \\
\text { lacking; no client data included; } \\
\text { no comparison areas/groups used. }\end{array}$ \\
\hline $\begin{array}{l}\text { Ball et al } \\
2009 b\end{array}$ & $\begin{array}{l}\text { Evaluation of the } \\
\text { North East } \\
\text { Lincolnshire } \\
\text { health trainer } \\
\text { service. }\end{array}$ & $\begin{array}{l}\text { Secondary analysis: synthesis of } \\
\text { published data on the effectiveness } \\
\text { of the health trainer scheme and } \\
\text { lay health promotion workers; } \\
\text { service performance data } 2008 \text { - } \\
2009 \text { (reporting on work by } 15 \\
\text { health trainers); published data, } \\
\text { guidance and pilot schemes } \\
\text { relating to the NHS Cardio- } \\
\text { vascular Health Check }\end{array}$ & As above. & $\begin{array}{l}\text { Paucity of published impact } \\
\text { evidence. Comparison of } \\
\text { performance data for } 2007-2008 \\
\text { and 2008-2009 affected by } \\
\text { limitations outlined above for } \\
\text { Ball et al } 2008 \text {. }\end{array}$ \\
\hline
\end{tabular}


Kime et al Evaluation of the 2008 Bradford district health trainers programme phase 2.

\section{Kitchen Evaluation of 2009 health trainer schemes in Cheshire and Merseyside.}

$\begin{array}{ll}\text { Meah and } & \text { Evaluation of a } \\ \text { Guest } & \text { health trainers } \\ 2010 & \text { scheme in } 10 \\ & \text { Primary Care } \\ & \text { Trusts across } \\ & \text { Greater } \\ & \text { Manchester. }\end{array}$

Programme; synthesis of qualitative data from 2 previous evaluations (Ball et al 2008, 2009a).

Secondary analysis of monitoring data concerning client characteristics, health issues and outcomes Jan 2006-Oct 2007.

Qualitative methods: in depth case studies of 3 localities using interviews and a focus group.

Secondary analysis of regional hub activity report 2008-2009.

Qualitative methods: semistructured interviews with key personnel in 8 Primary Care Trust areas (4 of which were currently operating a health trainer service); supplementary interviews with health trainers in 3 Primary Care Trusts.

Analysis of secondary sources: national policy documents, Greater Manchester strategy and service documents (reported activity), literature search and review.

Quantitative methods: survey of
Interviews with 20

health trainer clients, 9 health trainers, $11 \mathrm{key}$ informants, 3 senior health trainers and 4 project leads. Focus group with senior health trainers $(n=3)$, project leads $(n=4)$.

18 interviews with provider agencies, service commissioners and directors of public health. Supplementary interviews with health trainers (number not specified) and fieldwork visits.

Questionnaires completed by 99 health trainers (82\% response rate), 10 financial leads and 39 service users ( $9 \%$ response rate).
Monitoring data concerning clients' progress with action plans excludes 'active' clients (34\% of total); $11 \%$ of data is reported as missing. Sample of clients may not be representative.

Lack of detail about study methods; service performance data not included in the report; no client data included; no comparison areas/groups utilised.

Response rate to the health trainer survey inconsistent between Trusts. Response rate for service users low (9\%). Possible sample bias towards those with more positive experiences. 
health trainers, financial leads and service users.

Qualitative methods: nonparticipant observation of health trainers; semi-structured telephone interviews with service commissioners.

South et al Evaluation of an 2006, 2007 early adopter site in Bradford.

Analysis of secondary sources client monitoring data; health trainer feedback forms.

Qualitative methods: semistructured telephone interviews, focus groups, group interview and learning event.

\section{Visram and Geddes 2007}

Telephone interviews with 10 service commissioners (one in each PCT).

\section{2 focus groups involving 15 health trainers; telephone} interviews with 16 key informants from placement organisations (purposive sample); group interview with project leads; learning event with key

stakeholders; 22 clients followed up by telephone interview.

Purposive sample of 8 health trainers across 3 different models of service provision. The intention was to recruit members of the original cohort from early implementer sites but recruitment problems
Transferability of findings: intended to provide formative feedback to service; limited indepth exploration of issues; potential bias in client sample only those who attended followup and agreed to be interviewed (a minority of those eligible); sustainability of client behaviour change not evaluated.

Relatively small sample from one strategic health authority; volunteers not recruited for the study; descriptive nature of reflective diaries.
Qualitative methods - unstructured interviews, field notes, health trainers' reflective diaries. 


\begin{tabular}{|c|c|c|c|c|}
\hline & & & $\begin{array}{l}\text { meant that later cohorts } \\
\text { were included. }\end{array}$ & \\
\hline $\begin{array}{l}\text { Visram et } \\
\text { al } 2006\end{array}$ & $\begin{array}{l}\text { Evaluation of an } \\
\text { early adopter } \\
\text { scheme in the } \\
\text { North East of } \\
\text { England -across } 3 \\
\text { sites. }\end{array}$ & $\begin{array}{l}\text { Secondary analysis of } \\
\text { implementation documentation. } \\
\text { Qualitative methods - semi- } \\
\text { structured telephone interviews }\end{array}$ & $\begin{array}{l}\text { Semi-structured } \\
\text { interviews with } 17 \text { key } \\
\text { informants (identified } \\
\text { by project manager) } \\
\text { including project } \\
\text { managers, health } \\
\text { trainers' line managers } \\
\text { and supervisors, } \\
\text { community health } \\
\text { manager and a director } \\
\text { of public health. }\end{array}$ & $\begin{array}{l}\text { Views of health trainers not } \\
\text { included in the study; } \\
\text { respondents may not be a } \\
\text { representative sample; tendency } \\
\text { for respondents to reiterate } \\
\text { 'Choosing Health' messages. }\end{array}$ \\
\hline
\end{tabular}




\section{Page 29 of 29}

\section{Critical Public Health}

